
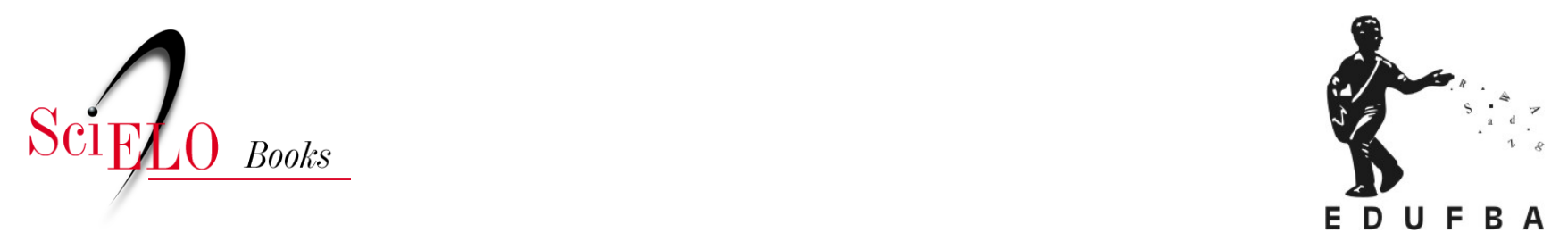

\title{
Psicologia e ciências humanas A Psicologia em uma perspectiva fenomenológica existencial: uma breve contextualização
}

\author{
Sílvia Raquel Santos de Morais \\ Carmem Lucia Tavares Barreto
}

\section{SciELO Books / SciELO Livros / SciELO Libros}

MORAIS, S.R.S., and BARRETO, C.L.T. A Psicologia em uma perspectiva fenomenológica existencial: uma breve contextualização. In: SANTIAGO, A.M.S., and FONSÊCA, A.L.B., comp. Psicologia e suas interfaces: estudos interdisciplinares [online]. Salvador: EDUFBA, 2016, pp. 61-89. ISBN 978-85-2322007-5. https://doi.org/10.7476/9788523220075.0003.

All the contents of this work, except where otherwise noted, is licensed under a Creative Commons Attribution 4.0 International license.

Todo o conteúdo deste trabalho, exceto quando houver ressalva, é publicado sob a licença Creative Commons Atribição 4.0. 


\section{A Psicologia em uma perspectiva fenomenológica existencial: uma breve contextualização}

Sílvia Raquel Santos de Morais, Carmem Lucia Tavares Barreto

\section{Introdução}

Este artigo originou-se de uma tese de doutorado que abordou a prática de psicólogos em oncologia pediátrica a partir de uma compreensão fenomenológica existencial. Portanto, o objetivo dele é contextualizar o percurso de consolidação da Psicologia em uma perspectiva fenomenológica existencial, tendo, como solo epistemológico, a ontologia hermenêutica de Martin Heidegger (18891976). Com isso, partiu-se da ideia esclarecedora de matrizes psicológicas de Figueiredo (1991), a qual apresenta a Psicologia a partir de uma compreensão que vai além das teorias e sistemas psicológicos.

Ao discorrer sobre o percurso histórico de desenvolvimento da psicologia como ciência independente e suas diversas propostas teórico-metodológicas consolidadas ao longo de 100 anos, Figueiredo 
(1991) organizou o pensamento psicológico a partir de três grandes matrizes: cientificistas, românticas e pós-românticas.

As matrizes cientificistas advêm das ciências naturais e tendem a desconhecer a especificidade do objeto de estudo da Psicologia em favor de uma "imitação” dos modelos dessa área. Sendo assim, a Psicologia acaba se diluindo no modelo metafísico, podendo tornar-se uma disciplina biológica. (MOREIRA, 2009) Essas matrizes priorizam e partem do pressuposto que existe uma verdade a ser alcançada por intermédio da razão e de um método científico, sua meta é atingir a ordem natural e comportamental dos fenômenos psicológicos, congregando o funcionalismo e o comportamentalismo.

Já as matrizes românticas e pós-românticas consideram a psicologia como ciência independente ao legitimar que seu objeto de estudo envolve atos e vivências humanas acompanhadas por seus significados. Essas matrizes congregam ainda três outras submatrizes: a vitalista, a naturista - na qual se inserem a Psicologia Humanista, a bioenergética, a Abordagem Centrada na Pessoa (ACP) e Gestalt Terapia (GT) - e as compreensivas - onde se inserem a fenomenologia, o historicismo idiográfico e o estruturalismo. Essas matrizes questionam a insuficiência dos métodos das ciências naturais para o estudo dos fenômenos psicológicos e privilegiam o estudo da experiência. Figueiredo (1991) ressalta que apenas o historicismo idiográfico pode ser definida como uma matriz romântica; as demais possuem uma inclinação pós-romântica ou antirromântica. Contudo, o elemento que unifica essas três submatrizes é a ênfase na experiência humana e em sua compreensão em um dado contexto cultural.

Figueiredo (1991, p. 33) discute sobre o campo da fenomenologia e suas incidências na Psicologia, esclarecendo a fenomenologia como "um dos coroamentos da tradição filosófica racionalista, iluminista e, portanto, anti-romântica”, que tenta superar o cientificismo e o historicismo. Já Penna (1997) nos ajuda a diferenciar a fenomenologia da fenomenologia existencial. Mas, antes dessa discussão, convém destacar um pouco do histórico da fenomenologia. Ela foi funda- 
da por Edmund Husserl (1859-1938) e a proposta da fenomenologia existencial advém de seu discípulo Martin Heidegger. Em Husserl, a fenomenologia surge como uma crítica à legitimação naturalista do conhecimento que se "voltava às coisas mesmas" no intuito de alcançar a essência dos fenômenos através da redução eidética/transcendental. Já em Heidegger, isso é descartado. Parte-se da ideia de que homem e mundo coexistem, e o questionamento do ser se dá através de uma compreensão ontológica, enfatizando-se o trânsito por entre a angústia e a insegurança do ser e não pela conceituação e representação próprias da metafísica. ${ }^{1}$

A fenomenologia não pode ser compreendida apenas como uma escola filosófica entre outras, mas também como uma metodologia de conhecimento. Para a fenomenologia, há uma coincidência entre ser (presença constante) e aparência e não entre ser e ideia, ou seja, o ser que se busca é manifesto nos modos-de-ser-no-mundo e não como uma mera coisa em si separada do mundo. Essa é uma diferença fundamental entre a orientação metafísica e a fenomenologia. ${ }^{2}$

Ao se falar na perspectiva fenomenológica existencial na Psicologia, remetemo-nos, inevitavelmente, ao campo da Filosofia. Desse campo, brotaram as principais fontes de inspiração para o surgimento da Psicologia. Contudo, a consolidação da psicologia dita científica só foi possível no século XIX com a separação da Filosofia e incorporação do modelo das ciências naturais. Mesmo Wilhelm Maximilian Wundt (1832-1920) tendo apresentado uma proposta de psicologia como

1 Metafísica vem de uma expressão grega e significa "as coisas depois da física", atribuída pelos editores de Aristóteles à obra em que trata da "primeira filosofia". Metafísica passou a significar "ir além das coisas físicas, naturais, dos entes". Nesse sentido, Heideg'ger critica a metafísica por ser uma ciência que estuda os entes, mas não o Ser. (INWOOD, 2002)

2 Fenomenologia: etimologicamente a palavra fenômeno vem da expressão grega phaionomenon derivada do verbo phainesthai, o qual significa: mostrar-se, vir à luz. A fenomenologia designa um método de investigação que estuda como o homem percebe aquilo que se mostra e como dá sentido às experiências. Fenomenologia é uma palavra que deriva de dois vocábulos gregos. "Fenômeno" significa aquilo que se mostra, não somente aquilo que se aparece ou parece. "Logia" deriva da palavra logos, que para os gregos tinha muitos significados: palavra, pensamento. (BELLO, 2006, p. 17-18) 
ciência intermediária entre as ciências naturais e as ciências sociais, predominou a influência das ciências da natureza, cuja principal meta era "atenuar" as interferências da subjetividade na prática científica. Mais tarde isso fez surgir um verdadeiro paradoxo: se por um lado a Psicologia precisava "adaptar-se/ajustar-se" ao paradigma positivista vigente para alcançar status científico, por outro lado, ela teve de lidar com uma questão delicada que envolvia eleger um objeto próprio de estudo (no caso, a subjetividade) para diferenciar-se das demais ciências e, ao mesmo tempo, tinha de "neutralizar tal subjetividade" o tanto quanto possível, a fim de alcançar independência, reconhecimento e destaque na comunidade científica. Vale ressaltar que, ainda hoje, grande parte da ciência é regida pelo paradigma positivista cartesiano que busca a essência das coisas sob a inspeção da "suposta neutralidade" e separação entre sujeito e objeto.

Assim, prossegue-se a história da ciência psicológica que se constitui a partir de um verdadeiro campo de dispersão de saberes e de uma multiplicidade de abordagens teóricas. Goto (2008, p. 176) nos esclarece tal questão:

[...] pela própria história da Psicologia científica, vemos que esta possui várias escolas e abordagens, muitas delas com o mesmo objeto, mas com resultados e propostas diferentes. Assim, a Psicologia ao mesmo tempo em que alcançou o lugar de ciência, tem seu lugar problematizado pelo fato de não ter chegado epistemologicamente a uma conclusão metodológica que garantisse a sua comprovação científica.

Ao se contemplar o percurso de consolidação da Psicologia, somos irremediavelmente lançados às suas diversas correntes de pensamento atravessadas pelas matrizes psicológicas anteriormente discutidas. Neste caso, recordaremos através de uma breve descrição, o campo da Psicologia Fenomenológica e da Psicologia Fenomenológica Existencial, além de outras incidências na Psicologia que costumam ser confundidas com essas por carregarem consigo influências do humanismo e da Filosofia Existencial. Façamos então essa breve diferenciação. 
A Psicologia Humanista despontou nas décadas de 1930 e 1940 a partir do movimento humanista, influenciando alguns psicólogos descontentes com as abordagens teóricas vigentes naquela época (psicanálise e o comportamentalismo). Contudo, é somente na década de 1950 que a Psicologia Humanista obteve seu reconhecimento a partir de seus iniciadores: Gardner Murphy (1895-1979), Gordon Williard Allpot (1897-1967), Abraham Maslow (1908-1970) e Carl Ranson Rogers (1902-1987). Tais autores começaram um movimento chamado de "terceira força" na Psicologia, em resposta aos rumos deterministas que a psicologia moderna vinha tomando ao afastar o homem do foco de suas discussões. Além disso, criticavam a noção de psiquismo tomada pelas duas primeiras forças (behaviorismo e psicanálise) e a ênfase demasiada nas patologias. (BUYS, 2007; FEIJOO, 2009)

De todos esses teóricos citados, Rogers (1983) destacou-se como um dos expoentes principais da Psicologia Humanista nos Estados Unidos, lançando um olhar sobre o humano a partir de sua própria experiência profissional no atendimento clínico a crianças, adultos e grupos. Além disso, lutou para que psicólogos americanos pudessem exercer psicoterapia e inaugurou a pesquisa sobre este campo na Psicologia. Sua abordagem centrada na pessoa ou centrada no cliente nos fala de uma perspectiva que obteve destaque, dada sua contribuição para a Psicologia Humanista. Sua forma de compreender o homem perpassa a ideia de que este é voltado para o crescimento e tende a desenvolver seus potenciais na presença de três condições facilitadoras:

1) autenticidade ou congruência;

2) aceitação positiva incondicional; e

3) compreensão empática.

Portanto, a ACP parte da concepção de um homem ativo voltado para a atualização de seus potenciais inatos.

Os indivíduos possuem dentro de si vastos recursos para a autocompreensão e para modificação de seus autoconceitos, de suas atitudes e de seu comportamento autônomo. Esses recur- 
sos podem ser ativados se houver um clima passível de definição, de atitudes facilitadoras [...] A abordagem centrada no cliente baseia-se na confiança em todos os seres humanos e me todos os organismos. (ROGERS, 1983, p. 38-39)

Apesar de Rogers (1983) ter ressaltado a importância da subjetividade, o resgate da experiência como "autoridade suprema” e a crença otimista no crescimento humano, mesmo assim foi criticado em suas raízes epistemológicas. Feijoo (2009, p. 53), por exemplo, fez a seguinte análise de sua perspectiva:

[...] essa proposta nos seus pressupostos mantêm a separabilidade homem-mundo com a ideia de um eu autêntico, que se localiza no interior do indivíduo como potencial e tendência à atualização e um eu inautêntico que se estabelece pelo impacto de um meio dificultador da expressão autêntica.

Outro autor que se destacou nessa esfera foi Abraham Maslow (1962), que partiu de uma concepção de homem que busca se autorrealizar e satisfazer suas necessidades. Para ele, isso acontece de forma hierárquica. Primeiro, o homem realiza as necessidades mais básicas (fome, sede e sexo), para depois satisfazer as necessidades de segurança (moradia), necessidades sociais (relacionamentos) e necessidades de estima (ser valorizado e amado), e, por último, ocorreria a autorrealização (satisfação diante das necessidades supridas).

Maslow (1962) rejeitou a posição positivista e naturalista do behaviorismo e assumiu uma posição humanista, concebendo o homem como pessoa e não como objeto ou fato determinado pelas leis do meio. Da psicanálise, critica a fragmentação e causalidade do psiquismo bem como o seu funcionamento através de mecanismos defensivos. (FEIJOO, 2009) Ao longo dos anos dedicou-se à Psicologia Humanista e ao movimento dos potenciais humano, tendo influências dos médicos Alfred Adler (1970-1937) e Kurt Goldstein (1878-1965), do psicanalista Erich Fromm (1900-1980), dos psicólogos Harry Harlow (1905-1981) e Max Wertheimer (1880-1943), além da antropóloga Ruth Benedict (1887-1948). Para ilustrar as contribuições de Maslow e 
seu ponto de vista sobre a Psicologia Humanista, transcrevemos abaixo um trecho de uma de suas obras:

Devo confessar que acabei pensando nessa tendência Humanista da Psicologia como uma revolução no mais verdadeiro e mais antigo sentido da palavra, o sentido em que Galileu, Darwin, Einstein, Freud e Marx fizeram revoluções, isto é, novos caminhos de perceber e de pensar, novas imagens do homem e da sociedade, novas concepções éticas e axiológicas, novos rumos por onde enveredar. Esta Terceira Psicologia é agora uma faceta de uma Weltanschauung geral, uma nova Filosofia da vida, uma nova concepção do homem, o começo de um novo século de trabalho (isto é, se conseguirmos sustar, entrementes, um holocausto). Para qualquer homem de boa vontade, qualquer homem 'pró vida', há um trabalho a ser feito aqui, efetivo, probo e eficaz, satisfatório, que pode proporcionar um significado fecundo à nossa própria vida $\mathrm{e}$ à dos outros. Essa Psicologia não é puramente descritiva ou acadêmica; sugere ação e implica conseqüências. Ajuda a gerar um modo de vida, não só para a própria pessoa, dentro da sua psique particular, mas também para a mesma pessoa como ser social, como membro da sociedade. De fato, ajuda a compreender até que ponto esses dois aspectos da vida estão realmente relacionados entre si. Fundamentalmente, a pessoa que fornece a melhor ajuda é a 'boa pessoa'. Quantas vezes, tentando ajudar, a pessoa doente ou inadequada causa, pelo contrário, sérios danos. Devo também dizer que considero a Psicologia Humanista, ou Terceira Força da Psicologia, apenas transitória, uma preparação para uma Quarta Psicologia ainda 'mais elevada', transpessoal, transumana, centrada mais no cosmo do que nas necessidades e interesses humanos, indo além do humanismo, da identidade, da individuação. (MASLOW, 1962, p. 10-11)

Como o humanismo 3 é um movimento muito amplo que procura apreender o homem naquilo que o distingue de todos os demais,

3 O humanismo surgiu no renascimento entre os séculos XIV e XV e designa um conjunto de doutrinas que tratam a respeito da origem, natureza e destino do homem. É uma filosofia que se concentra nos meios humanos de compreender a realidade e de buscar o conhecimento, 
isso abre espaço para que a Psicologia Humanista não possua um corpo teórico próprio, chegando a reunir várias linhas de pensamento (BUYS, 2007; ERTHAL, 1986, 1989) e a congregar ideias da Filosofia Existencialista.

Diante disso vemos que a Filosofia Existencialista, apesar de possuir pontos divergentes do humanismo, foi incorporada em algumas discussões da Psicologia Humanista, tendo em vista alguns pontos de convergência. Sendo assim, faz-se necessário destacar pelo menos alguns desses pontos. Erthal (1989) comenta que, nessas duas correntes, o homem é visto como fonte e centro de valores que está em permanente fluxo, como uma forma de superar a si mesmo. Concordam que há uma direção para o crescimento e para a relação com seus pares. Outros princípios comuns às duas correntes são a confiança na capacidade de escolha do indivíduo, seu crescimento, responsabilidade pelas ações e envolvimento com elas. E quanto aos pontos divergentes, a autora salienta que no humanismo prevalece a concepção positiva do homem voltado para uma tendência inata ao crescimento e desenvolvimento de potencialidades. Já o existencialismo se mantém numa postura menos "otimista" ao ver o homem como ser responsável pelas suas escolhas, além de tratar, mais especificamente, de temas como angústia e morte.

Embora as ideias de Erthal (1989) e de Greening e seus colaboradores (1975) circulem em torno de certo hibridismo entre a Psicologia Humanista e a Psicologia Existencial, salienta-se que essa é uma questão epistemológica polêmica que ultrapassa o foco desse artigo. Por isso, não iremos nos deter em tal impasse. No entanto, citamos um posicionamento de Feijoo (2009, p. 53) que nos aproxima desse impasse na tentativa de esclarecê-lo:

Parece que o modo como estas Psicologias tentam resolver a questão da determinação psíquica e sua fragmentação fracassa, já que acabam por reincidir nas questões por ela criticadas, uma vez que mantêm os pressupostos metafísicos que

considerando o homem como um ser valioso, centro de seus estudos e preocupações filosóficas. (PEREZ, 2004) 
pretendiam combater: a substancialização do sujeito e a premissa da possibilidade se saber o que lhe faz bem ao homem. Logo há uma determinação daquilo que faz bem ao homem, ou seja, defender sua humanidade e de que há um homem e que se pode definir o que ele é e como deve ser.

Convém, agora, explicitar o existencialismo em favor de uma compreensão mais precisa de seus contornos. Antes disso, mencionaremos conforme Casanova (2009, p. 90) as origens da palavra existência: "existir provêm de ek-sistir, que significa literalmente ser para fora."

A Filosofia Existencialista surgiu em meados do século XIX e início do século XX como reação ao idealismo hegeliano e a partir das ideias de seus precursores Soren Kierkegaard (1813-1855) e Friedrich Nietzsche (1844-1900), tendo seu apogeu na época da Segunda Guerra Mundial. Kierkegaard, apesar de ser um dos pioneiros, trouxe discussões sobre problemáticas como o subjetivismo, o sentido da existência, a angústia, o tédio, a morte, a melancolia, a liberdade, dentre outros. Tais discussões tinham como foco o homem concreto em sua singularidade. E, mais contemporaneamente, encontramos outros filósofos com ideias distintas. Para esclarecer tal questão, recorremos a Giordani (1997, p. 15-16):

Em Heidegger, Marcel e Sartre notamos claramente a influência do método fenomenológico de Husserl embora não participem da tese de Husserl, nem sequer de sua posição fundamental. Também a chamada filosofia da vida influi poderosamente no Existencialismo: Bergson, Nietzsche e Dilthey, sobretudo representam outras tantas influências decisivas para os existencialistas.

O existencialismo, enquanto doutrina ético-cultural e literária, ressurgiu como movimento filosófico no período entre as duas guerras mundiais, difundindo-se nos Estados Unidos e na Europa, sobretudo na Alemanha e na França. De um modo geral, o existencialismo, segundo Giordani (1997), alertou-nos para a existência humana 
como algo diferente de tudo o que existe no mundo e também para os problemas cotidianos que afligem o homem, valorizando a sua realidade subjetiva. Ainda nesse sentido, “o Existencialismo representa até um dado ponto, uma sadia reação demonstrando que nem tudo é abstração e razão, que a vivência, a experiência, a intuição e até mesmo o irracional têm também seu lugar no ser humano". (GIORDANI, 1997, p. 133-134)

Martin Buber (1878-1965), Karl Jaspers (1883-1969), Gabriel Marcel (1889-1973), Edmund Husserl (1859-1938), Jean Paul Sartre (1905-1980), Simone de Beauvoir (1908-1986) e Albert Camus (19131960) tiveram grande importância no existencialismo francês, sendo influenciados por Kierkgaard e pelo método fenomenológico.

No existencialismo, a essência não determina o homem e sua premissa básica é que "a existência precede a essência”. (SARTRE, 1989) O homem é um eterno "vir a ser" que não possui uma essência, pelo contrário, ele é quem se constrói na medida em que existe e escolhe. O homem é visto como livre para escolher e, consequentemente, responsável por suas escolhas. O passado não é garantia do presente e tampouco do futuro. Diante disso, a angústia é inevitável.

A incidência do existencialismo na Psicologia fez surgir uma nova proposta chamada de Psicologia Existencial, preconizada, sobretudo, pelo psicólogo americano Rollo May (1909-1994) em oposição às explicações teóricas abstratas de inspiração científico-natural. Suas obras foram associadas à Psicologia Humanista, mas traziam diferenças dessa corrente, pois utilizava alguns conceitos filosóficos advindos das obras de Kierkegaard e Nietzsche. Além disso, organizou a obra Psicologia existencial, a qual se tornou um clássico que congregava diversos autores da área. Segundo Rollo May (1988), a Psicologia Existencial consiste em uma atitude que impregnou quase todos os ramos de terapia na América. Assim, o ponto de vista existencial requer um esforço para compreender a experiência humana, focando na pessoa existente, emergente, em evolução. Em suma, 
O Existencialismo é uma atitude, uma abordagem dos seres humanos, não uma escola ou grupo especial. Também não é um sistema de terapia, embora lhe dê subsídios relevantes. Não é um conjunto de técnicas, embora possa dar-lhes origem. É antes uma preocupação em compreender a estrutura do ser humano, e sua experiência, à qual deve, em maior ou menor grau, estar subordinada toda a técnica. (MAY, 1988, p. 21)

Para Feijoo (2009), Rollo May foi influenciado pelo movimento humanista americano e pelo existencialismo europeu. Do humanismo, herdou a ênfase na totalidade e singularidade da pessoa e do existencialismo, adotou o estudo de temas como liberdade, responsabilidade e angústia. Assim, a Psicologia sofre influências diretas desses dois modos de se pensar o humano. Exemplo disso é dado por Lessa e Sá (2006) ao afirmarem que a Psicologia Existencial prioriza a existência concreta do humano, ultrapassando concepções teóricas que são muitas vezes abstratas e distantes da realidade de um contexto na qual o psicólogo está inserido.

Os conceitos fundamentais do existencialismo giram em torno de temas como liberdade, escolha, responsabilidade, angústia, solidão, morte, sentido da vida, autenticidade e inautenticidade, subjetividade. Assim, o existencialismo aproxima a Psicologia de uma reflexão que remonta à sua fonte que é a Filosofia, anunciando um novo jeito de abordar a experiência humana a partir da concretude cotidiana.

Vale ressaltar que o existencialismo não é apenas uma doutrina filosófica, mas uma atitude enraizada no interior do homem que mostra uma ligação primordial da existência com a coexistência, bem como a possibilidade de isolamento do humano. Articula-se com a tradição filosófica ao afirmar o valor do presente e das escolhas. Nas palavras do filósofo Abbagnano (2006, p. 43):

O Existencialismo parte justamente do concreto, do eu individualmente existente, de mim mesmo enquanto busco e pergunto. Para o Existencialismo o filosofar é decisão que diz respeito a minha atitude, a minha relação real e concreta com o ser. 
Na compreensão de Sá (2010), apesar de reunir um conjunto de doutrinas, segundo as quais, a Filosofia tem por objetivo a análise e a descrição de temas da existência, “o Existencialismo nunca se constituiu como um sistema filosófico estruturado, valorizando antes, o próprio filosofar enquanto atitude permanente de estranhamento e interrogação do sentido.” (SÁ, 2007, p. 322)

Isso corrobora com a visão do filósofo Jolivet (1953, p. 153) ao argumentar que:

Há várias formas de Existencialismo que, à primeira vista, parecem contradizer-se, e, por outro, a própria ideia de Existencialismo reveste, por sua vez, múltiplas significações, em que o essencial e o acidental andam de maneira tão misturados que são aparentemente indiscerníveis.

Feijoo (2009) nos aponta que alguns existencialistas recorreram ao método fenomenológico como uma forma de suspender qualquer juízo a priori do que seja o homem, partindo da premissa de que homem e mundo são inseparáveis.

Agora, com o devido esclarecimento acerca do humanismo e do existencialismo e de suas incidências no campo psicológico, ilustraremos um pouco de como a Psicologia foi incorporando a fenomenologia em seu campo teórico-prático.

A fenomenologia é, antes de tudo, uma possibilidade de interpretação do real, que trilhou um caminho particular em direção a uma metodologia que a diferenciasse da Psicologia, e, ao mesmo tempo, estabeleceu conexões com a mesma. (GOTO, 2008) E, no tocante a essas nuances, a fenomenologia surge em contestação ao método experimental positivista. Desde sua aparição em 1900, a fenomenologia esteve presente em muitas tendências filosóficas, Lambert, Hertz, Kant, Hegel, Teilhard, Chardin, dentre outros, e desmembrou-se em várias definições. Mas é somente a partir da fenomenologia transcendental de Husserl e, mais tarde, de sua analítica intencional, que a Psicologia Fenomenológica inicia seu legado. Sua proposta foi uma tentativa de fazer a Filosofia adquirir o estatuto da razão absoluta e de 
conferir bases para as ciências positivistas, fundamentando o conhecimento e a fenomenologia como uma espécie de "positivismo superior”. (DARTIGUES, 2008) Além disso, a crise das ciências e da Psicologia anunciada por Husserl, e que persiste até hoje, contribuiu para o surgimento da fenomenologia. Tal crise é marcada pela tentativa de conciliar a objetividade com a subjetividade, ou seja, em buscar se tornar uma ciência da subjetividade. (GOTO, 2008)

O contexto de surgimento da fenomenologia foi marcado por limitações teóricas e metodológicas, uma vez que naquela época não havia propostas que abrangessem a subjetividade na origem do seu sentido. Foi somente com a crise da razão e com o descrédito científico amargado pela Filosofia que Husserl propôs o método fenomenológico baseado na "volta às coisas mesmas", numa tentativa de deixar ver por si mesmo o que aparecia na experiência, ou seja, sua ênfase recaía na intuição como elemento essencial da atitude filosófica. (SÁ, 2007) Segundo Zilles (2008, p. 19), “a Fenomenologia pretende ser ciência das essências e não dos fatos. É ciência de experiência, que descreve os universais que a consciência intui quando lhe apresentam os fenômenos."

O próprio Husserl citado por Goto (2008) argumentou sobre a importância da fenomenologia para a investigação científica, e mais especificamente, para a Psicologia. Na obra A crise das ciências europeias, ele critica o objetivismo científico e denuncia a crise das ciências europeias. Para tanto, propõe, como alternativa, a fenomenologia enquanto "Filosofia primeira" e método, através da qual o conhecimento passa a ser construído em referência à subjetividade e não mais restrito ao projeto racional. Goto (2008, p. 74 ), ao comentar sobre a fenomenologia husserliana, assinala que:

[...] a fórmula inicial da Fenomenologia não tem a pretensão de negar o conhecimento construído na ciência e na Filosofia, apenas requer para si o direito de excluir qualquer perspectiva teórica sobre as coisas para que se possa ir espontânea livremente até elas [...] em favor da eliminação dos prejuízos e preconceitos 
Barreto (2006) nos diz que a fenomenologia foi se constituindo não apenas como um método com procedimentos e instrumentais definidos, mas como uma proposta diluída na obra de seus pensadores - Edmund Husserl, Emanuel Lévinas (1906-1965), Maurice Merleau-Ponty (1908-1961), Heidegger e Paul Ricoeur (1913-2005). Enquanto que Husserl nos diz que a fenomenologia designa a ciência dos fenômenos que investiga aquilo que aparece à consciência em todas as suas significações possíveis.

Concordamos com a visão de Goto (2008) ao afirmar que a Psicologia Fenomenológica proposta por Husserl continua obscura e sem desenvolvimento pleno, necessitando de maiores esclarecimentos. Segundo Penna (1997, p. 80),

[...] Husserl acredita ter descoberto uma consciência (a transcendental) que não reside no mundo (não é parte dele), mas é inteiramente independente da consciência empírica, do mundo empírico, da Psicologia humana, da biologia e da história.

Apesar disso, muitas ideias de uma "fenomenologia pura" husserliana contribuíram para a emergência de fenomenologias da percepção, da religião, das relações interpessoais e dos transtornos psicológicos. (SÁ, 2007)

\section{A ontologia de Martin Heidegger e suas relações com a Psicologia}

Diante dessa breve explanação da fenomenologia husserliana, faz-se necessário elucidar discussões a respeito da ontologia hermenêutica ${ }^{4}$ ou analítica existencial heideggeriana, realçando, com isso, aspectos convergentes e divergentes dessas propostas.

4 Hermenêutica: Em Heidegger (1999), hermenêutica consiste em dar a conhecer o encobrimento originário (movimento de ocultação e desocultação dos entes), ou seja, consiste em encontrar uma interpretação que dissolva esse encobrimento originário. Sendo assim, trata-se de uma hermenêutica da faticidade, já que empreende esforços para compreender a vida concreta como fenômeno. 
A partir de 1909, Heidegger se interessou pela fenomenologia de Edmund Husserl. Segundo Sá (2010, p. 2, grifo do autor):

[...] sua fascinação e inquietude pelos escritos de Edmund Husserl - seu professor e fundador do método fenomenológico - culminaram no abandono do estudo teológico e dedicação à Filosofia. A partir da leitura de 'Investigações Lógicas' de Husserl, compreendeu que o mostrar-se dos fenômenos poderia ser considerado como o redescobrimento do traço fundamental do pensamento grego: alétheia (desvelamento).

Isso traz à tona uma verdadeira ruptura com o modo de pensar metafísico, já que Heidegger parte do cotidiano e não de conceitos abstratos para gerar conhecimentos acerca da existência humana. Para ele, o homem não pode mais ser compreendido em termos de mera objetivação, seja ela biológica, psicológica ou sociológica, uma vez que "o existir humano nunca é um objeto simplesmente dado em algum lugar, muito menos encapsulado em si mesmo”. (HEIDEGGER, 1999, p. 33)

Em linhas gerais, Gonçalves, e colaboradores (2008, p. 431) destacaram que a ontologia heideggeriana é hermenêutica, já que:

O sentido que se desvela através do homem, nunca se dá a partir de algum a priori transcendental, ele só é na medida em que se desvela historicamente. Isto porque para Heidegger (2001) o que caracteriza o modo de Ser do homem, a existência, é justamente o fato de que seu sentido está sempre em jogo no tempo.

Heidegger aproximou-se de Husserl ao lançar mão do método fenomenológico e ao propor passar da descrição pura dos fenômenos para a interpretação dos mesmos. Contudo, Heidegger distanciou-se do uso do método tal como empreendido por Husserl e rejeitou as propostas de redução fenomenológica, pois essa redução operava com base em uma "suposta neutralidade" que negava e excluía exatamente o que mais interessava a Heidegger: a existência enquanto é no mundo. Assim, Heidegger buscou desenvolver: 
1) uma ontologia que retomasse e aprofundasse a discussão empreendida até então pelos gregos;

2) uma investigação do significado da angústia; e

3) uma reflexão sobre o problema da temporalidade. (PENNA, 1997)

Na visão de Feijoo (2009, p. 56), a fenomenologia de Husserl e a ontologia heideggeriana:

[...] parecem apontar para elementos que possibilitam a edificação de uma Psicologia Fenomenológica Existencial, em dois aspectos fundamentais: a atitude antinatural e o ser-aí tal como tomado por Heidegger, para indicar a impossibilidade de dicotomizar homem e mundo.

Já Michelazzo (2010, p. 85-86), de forma sintética, realça alguns dos principais pontos de divergência entre Husserl e Heidegger:

Para Heidegger, a vida em sua realidade histórica escapa ao conhecimento transcendental, tal como Husserl entende, por reduzi-la à condição de objeto, cuja origem é sempre, em última instância, o sujeito que o representa. Tal procedimento está assentado sobre o pressuposto de que a dimensão histórica e fáctica podem ser excluídas da constituição eidética que se encontra na consciência que, por sua vez, acha-se sustentada por um fundamento a-histórico absoluto. Assim, esse processo metodológico, que quer ocupar-se exclusivamente das essências, desenraizado da experiência da vida, esquece as suas próprias suposições. É verdade que Husserl fala de vida, mas a vida de um eu puro, nunca a vida imediata, a vida do mundo. Esta vida real, concreta, tal como Heidegger a pensa, não pode ser captada por uma intuição eidética, mas sim por uma aproximação compreensiva. Assim, se a fenomenologia de Husserl é um esforço para ver objetividades - ou seja, reconduzir objetos à consciência pura -, a vida, como tal, no entender de Heidegger, desaparece. Para apreender essa vida real, Heidegger substituirá a Fenomenologia transcendental por uma Fenomenologia Hermenêutica. 
Para Loparic (2004), os motivos que levaram Heidegger a romper com a fenomenologia husserliana se devem ao pensamento "objetificador" de Husserl e em sua proposta de apreender a faticidade da vida humana através da intuição categorial. Na ótica heideggeriana, isso deveria ser revisto, pois a "Filosofia não deve orientar-se unilateralmente nem pela matemática ou ciências naturais nem pela história”.

Diante disso, compreendemos a influência e a contribuição significativa de cada um desses dois filósofos para a fenomenologia e para o saber-fazer psicológico. Mesmo diante da fragmentação do campo psi e do pluralismo de abordagens que foram surgindo ao longo dos anos (BARRETO; MORATO, 2009), sabemos que a fenomenologia husserliana inspirou a Psicologia Fenomenológica, enquanto que a ontologia heideggeriana inspirou o pensar da Psicologia em uma perspectiva fenomenológica existencial.

\section{Heideg'ger e suas influências para a Psicologia em uma perspectiva fenomenológica existencial}

[...] uma grande contribuição da Psicologia fenomenológico Existencial é a de evitar que a Psicologia se afogue num mar de teorias que perderam o contato com o cotidiano e com a experiência mesma do existir humano. Isto porque para $\mathrm{Fe}-$ nomenologia apenas o que pode ser visto ou experimentado é real. A verdade da existência não é atingida por um exercício intelectual; ela é revelada ou desvelada nos próprios fenômenos. (GONÇALVES et al., 2008, p. 431)

A vida e as obras de Heidegger repercutiam no âmbito das ciências humanas e da psiquiatria. Contudo, sua obra de maior destaque foi Ser e tempo (publicada pela primeira vez em 1927), por apresentar sua principal preocupação: a questão sobre o sentido do ser. Ainda hoje, suas ideias são consideradas originais e críticas da sociedade tecnológica do século XX, mesmo que em alguns momentos tais ideias tenham soado de forma obscura e inacabada para alguns es- 
tudiosos e, ao mesmo tempo, relevantes e originais para outros. Tais ideias situam-se no centro das preocupações filosóficas da contemporaneidade ao discutir o sentido do ser e criticar o paradigma metafísico em seu modelo de ciência.

A incursão de Heidegger pela fenomenologia contribuiu para que o mesmo abordasse a questão do ser por uma via diferente daquela percorrida pela metafísica, uma vez que não interroga a respeito do que é o ser, mas sim sobre o sentido do ser. (SÁ, 2010) Ou seja, enquanto a metafísica concebe a questão cognitiva apenas sob o prisma do cogito (intelecto, razão), Heidegger trata da questão cognitiva sob a ótica existencial. (CRITELLI, 2007)

Heidegger empreendeu esforços na superação do paradigma metafísico vigente no pensamento ocidental desde os tempos de Platão e Aristóteles. Apesar do domínio da técnica/tecnologia, o paradigma metafísico carece de abordar o sentido e o valor das coisas para o homem (MICHELAZZO, 2010), desprezando, assim, o caráter de provisoriedade, mutabilidade e relatividade da verdade.

De acordo com Heidegger (1967, p.153), “[...] a Metafísica não questiona a verdade do Ser em si mesmo”. Para ele, é necessário que o conhecimento esteja apoiado na própria experiência concreta do existir, sem que haja dicotomia homem versus mundo. Assim, as esferas distintas do real passam a ser pensadas como um todo/uma unidade que constitui a mesma realidade. Para tanto, seria necessário libertar o pensar de fatores condicionantes que o impedem de ir além da investigação do ente. O desafio consiste, portanto, em construir a máxima unidade entre ser e ente, de modo a superar o pensamento metafísico e inaugurar outro modo de pensar, denominado de pensamento originário. (MICHELAZZO, 1999)

Pensamento originário é uma expressão que nos remete ao movimento que Heidegger fez ao retomar filósofos gregos, e, assim, resgatar o pensamento originário do ser. Portanto, o pensar originário é proposto por Heidegger como um retorno ao ser, que é a fonte de onde brotou o pensamento ocidental. (MICHELAZZO, 1999) 
Segundo Michelazzo (1999), o círculo hermenêutico é a forma pela qual Heidegger se apropria e entende a fenomenologia. O círculo hermenêutico apresenta-se como integrante do pensamento originário, ou seja, nele está presente o pensar original que parte da explicitação da experiência e de seus desdobramentos, e não de demonstrações, explicações ou provas.

O modo de pensar guiado pelo círculo hermenêutico choca-se contra toda uma tradição de pensamento, pois ele não parte de uma afirmação prévia e devidamente fundamentada para, em seguida, serem derivadas outras proposições por meio da demonstração [...] Afastar-se do círculo hermenêutico por achá-lo complexo ou ambíguo é, antes de tudo, distanciar-se das estruturas originárias que determinam a essência do homem. (MICHELAZZO, 1999, p. 114 - 116)

No círculo hermenêutico, considera-se o movimento de ocultação e revelamento dos fenômenos, já que um ente nunca se mostra completamente; daí a impossibilidade de se adotar uma teoria a priori que sistematize a condição humana. (ALMEIDA, 2005) Portanto, na fenomenologia empreendida por Heidegger, os fenômenos são refratários à teoria, havendo lugar para admissão do mistério, das lacunas, das incertezas e das mudanças como questões inerentes ao movimento de existir e de pensar. Vale ressaltar que é comum denominar a fenomenologia empreendida por Heidegger como fenomenologia existencial.

Retomando a metafísica e tentando fazer um paralelo com a fenomenologia, Almeida (2005) destaca que a metafísica pressupõe uma relação dicotomizada sujeito versus objeto, atendo-se à logicidade do ser e aos aspectos representativos da realidade. Em contraponto, a fenomenologia:

Heidegger questiona os dogmas de modos de ser, tendo o tempo e não o intelecto como horizonte, no qual tudo o que é está num contínuo movimento de patentear-se e esconder-se. Um aspecto importante a ser ressaltado é que, sob a ótica Fenomenológica, a relatividade, deixando de Ser um 
problema, torna-se a própria circunstância de aparição dos entes, implicando na provisoriedade daquilo que vem a Ser e que está sendo. (ALMEIDA, 2005, p. 33)

Segundo Barbosa (1998) a relevância do pensamento heideggeriano deve-se à problematização do "ser-em”, ou seja, do ser em coexistência com o mundo, constituindo o que ele denominou de analítica do Dasein (ser-aí). O ser é assim como o nada, na medida em que não nos diz algo de concreto, tangível/efetivo e, ao mesmo tempo, envolve significados como viver, surgir e permanecer. (MICHELAZZO, 1999) A fim de esclarecer o que Heidegger chama de ser e de ente, destacamos:

Ente é tudo de que falamos de que entendemos, com que nos comportamos dessa ou daquela maneira, ente é também o que e como nós mesmos somos. Ser está naquilo que é e na realidade no Ser simplesmente dado, no teor e recurso, no valor e validade, na presença, no há. (HEIDEGGER, 1999, p. 32) Ser é o possível. Como o elemento, o ser é a força silenciosa do poder que quer, isto é, do possível. (HEIDEGGER, 2009, p. 30)

Universalidade, a impossibilidade de definição e evidência do conceito de ser. (SÁ, 2010) Traz também questionamentos provocadores de experiências, exigindo um verdadeiro “[...] abandono de opiniões habituais da Filosofia”. (HEIDEGGER, 2009) Há sentidos inerentes ao verbo "ser", subjacente às suas variedades de usos. Suas concepções quanto ao que existe constituem uma ontologia hermenêutica oriunda de pesquisas acerca dos filósofos pré-socráticos, da Filosofia de Platão e de Aristóteles. Além desses autores, Heidegger também estudou sobre o filósofo Franz Brentano (1838-1917) e a Filosofia cristã medieval (escolástica), sendo influenciado, ainda, por diversos filósofos do século XIX e início do século XX, principalmente pelo pensador católico dinamarquês Soren Kierkegaard (1813-1855) e pelos alemães Friedrich Nietzsche (1844-1900) e Wilhelm Dilthey (1833-1911). 
Heidegger (1999) discute o que significa ser para o homem, ou “como é ser”, mesmo considerando que o ser seja uma questão universal, indefinível e que tende a aparecer como algo estranho e supérfluo pela mentalidade que dominava a Alemanha naquela época. Seu intuito é então levar o homem a fazer essas perguntas com envolvimento e reflexão. Sem refletir sobre o ser, o homem aliena-se e segue uma maneira inautêntica de ser e vai, aos poucos, apegando-se aos encantos da técnica e às promessas dos "supostos avanços" científicos, sendo transposto para outra realidade onde o mundo passa a ser um objeto e as relações se tornam meramente técnicas.

Pasqua (1993), baseado em Heidegger, comenta que o ser reside no "quê" e no "quem”, naquilo que existe e subsiste. É o ser que torna possível a abertura para a compreensão da existência humana. Stein (1979), por sua vez, afirma que, para Heidegger, o ser é semelhante a uma casa habitada pelo homem, uma espécie de clareira que desponta no meio de um bosque, ou seja, “[...] é presença permanente, horizonte luminoso, no qual todos os entes encontrariam sua verdade”. (STEIN, 1979, p. 11)

Na ótica do ser-no-mundo (Dasein), o significado não está nas coisas, mas no sentido que surge da coexistência do homem com estas coisas. Ser e mundo são, portanto, dimensões constitutivas do homem. O sentido do ser está vinculado à abertura para compreensão que cada um tem de si mesmo, do outro e do mundo. O sentido em si não pode ser compreendido, mas é aquilo que pode se articular na abertura da compreensão, portanto, não é algo evidente por si mesmo, mas o princípio/direção que norteia a apreensão do ser e dos entes: em outras palavras, é uma compreensibilidade do que é articulado no discurso. O sentido do ser está ligado à linguagem e não é encontrado fora dela.

Já a compreensão é o poder-ser, a visão do homem permeada pela linguagem enquanto dimensão constitutiva do ser e ocorre na coexistência e numa determinada disposição afetiva. "Em toda compreensão de mundo, a existência está compreendida e vice-versa." 
(HEIDEGGER, 1999, p. 209) Na medida em que nos apropriamos da compreensão e elaboramos suas possibilidades, chegamos ao que Heidegger chamou de interpretação. Assim, a interpretação se funda numa posição, visão e concepção prévia e nunca está isenta de pressuposições.

Partindo dessas noções, teríamos a analise do Dasein como uma analítica existencial, cujo núcleo principal se encontra no emprego do método fenomenológico em prol da investigação da existência humana. (BARBOSA, 1998)

A analítica existencial heideggeriana foi chamada de Daseinsanalytik ou Daseinsanalyse. Essa expressão apareceu pela primeira vez na obra Ser e tempo (1927/1989) e permaneceu assim denominada até hoje. Baseados em Heidegger, Mattar e Sá (2008) afirmam que a analítica do ser do homem, tais como: a abertura original do Dasein ao mundo, a compreensão e a disposição afetiva, o ser-com-o-outro, o cuidado, o ser-para-a-morte, a temporalidade e a espacialidade originais, além da corporeidade.

Quanto à abertura original do Dasein ao mundo, Heidegger (2001) afirma que o existir como Dasein não é passível de objetificação e caracteriza-se pela abertura para "[...] poder-apreender as significações daquilo que aparece e que se lhe fala a partir de sua clareira”. (HEIDEGGER, 2001, p. 33) Em outras palavras, o homem é um ser que tem a abertura como condição ontológica. A partir dessa abertura, manifesta-se a disposição afetiva, compreensão e discurso (HEIDEGGER, 1999), cujos correlatos ônticos/empíricos são afeto, desejo, conhecimento e linguagem. (BARBOSA, 1998)

A condição de estar lançado no mundo (de existir) é por si só angustiante, bem como a condição de se produzir conhecimento, pois isso, inevitavelmente, remete esse homem à sua condição de ser finito. Em outras palavras, o homem é limitado por circunstâncias que compreendem o seu mundo compartilhado, sendo levado a pensar sobre a dimensão futura e a lançar-se ao seu encontro. Nesse chamado, o ser se projeta e se vê sempre como limitado no tempo, mortal, frágil, 
incompleto e angustiado. (DUARTE; NAVES, 2011) E mesmo sem sequer ter escolhido existir, como, com quem e onde existir, o homem é lançado no mundo e convocado a produzir sentidos em sua existência. Sendo assim, a única certeza que ele traz consigo é a possibilidade, e enquanto possibilidade, esta se apresenta como o nada/vazio. E isso o angustia sobremaneira, obrigando-o a se desfazer da "ilusão de imortalidade" até mesmo quando busca "certezas científicas".

Sendo assim, o homem é colocado diante da própria finitude, o que, não raro, desperta-lhe estranheza e inquietude, remetendo-o às incertezas, à impossibilidade de controle absoluto sobre a vida, uma vez que algo sempre lhe escapa do domínio. Ao mesmo tempo em que a angústia é algo que literalmente apavora e é tirada de cena, é algo que também desperta o humano em direção ao seu poder-ser mais próprio. É a partir da angústia que o homem é chamado a conferir sentidos para a vida. Ela nos "aponta e desperta" para aquilo que o cotidiano "tenta nos anestesiar e desviar".

O mundo apresenta-se de modo ambíguo para o humano. Se, por um lado, é aparente solidez, prestando-se como meio e abrigo, por outro, apresenta-se como fluidez na medida em que o sentido de ser se dilui. Por conseguinte, não há uma pertença do homem ao mundo, o qual lhe parece, por vezes, inóspito. Esse não pertencimento aparece sob a forma de experiência de desabrigo, desamparo e abandono, denominada por Heidegger de angústia. É a angústia que lança o homem frente a suas próprias possibilidades de ser, ou seja, frente à sua liberdade. Assim, tanto a inospitalidade do mundo quanto a liberdade humana constituem condições ontológicas do ser. (ALMEIDA, 2005)

Nunes (2004) nos diz que a angústia é o encontrar-se fundamental que coloca o homem diante do nada e o faz retroceder "diante de algo". A angústia é quando o nada se torna manifesto. Além disso, difere-se do medo. No medo há um objeto definido, enquanto que na angústia não há, é o próprio nada que se apresenta. Cipullo (2000, p. 94) sintetiza a questão da angústia em Heidegger ao comentar: 
É a angústia que lança as estruturas de toda e qualquer possibilidade de temor; trata-se de uma disposição afetiva originária que coloca o Dasein (ser-aí, existência humana) diante do nada, de sua própria incompletude e abertura. O que angustia o homem, na verdade, é o próprio mundo em que foi, sem opção, lançado, e do qual será, mesmo contra sua vontade, arrancado. O homem é então um ser-para-a-morte. Todo temer é, conseqüentemente, em essência, temer a morte, saber da certeza da morte [...] Toda angústia é para Heidegger, angústia de morte. Vivemos fugindo da morte. Fugindo da morte, vivemos.

Diante disso, podemos compreender que Heidegger coloca o homem como um ser de projeto, voltado para o futuro. Existir é um projeto que agrega a compreensão enquanto estrutura originária do Dasein. É na compreensão, e também por ela, que nos movimentamos e criamos espaços para poder-ser. Nas palavras de Sá (2010, p. 6), “[...] a cada modo de existir, corresponde uma significação possível do mundo".

É nessa projeção para o "vir-a-ser" e no embate com a morte que o homem se apropria do seu projetar-se diante da vida. É por saber que tem um tempo a gastar que o homem planeja, sonha, idealiza, espera e luta por realizações, embora não tenha garantias de que isso ocorrerá um dia. "Admitir" que a vida não existe sob a ótica da garantia, mas sob a ótica da possibilidade não é tarefa simples. Mas, ao apropriar-se dessa condição (enquanto existência lançada) e assumi-la, o homem destina-se na busca de si mesmo.

O modo de ser oriundo do desvelamento (Aletheia) ocorre quando o homem se apropria de sua condição de ser finito e angustiado, assumindo a responsabilidade perante suas escolhas, encarando e resignificando o "nada" que se lhe apresenta no cotidiano de modo próprio/pessoal e não conforme o "a gente”, o “todos nós”. Já o modo de ser decaído é quando não assumimos essa condição de ser- para-a-morte, e nos perdemos na impessoalidade, lidando com os fenômenos de forma superficial e igualando-se à massa, ao público. 
Para Heidegger, permanecemos nesse modo-de-ser na maior parte do tempo, no qual somos absorvidos pela impessoalidade/inautenticidade. Apesar disso, podemos também buscar nosso ser-si-mesmo-próprio, singular, autêntico. Portanto, na ótica heideggeriana, a existência humana acontece ora em movimentos autênticos/próprios, ora em movimentos inautênticos/impróprios. Na impropriedade, somos facilmente tragados pelo falatório, curiosidade e ambiguidade, e na propriedade, somos compelidos a cuidar de ser.

\section{Considerações finais}

A perspectiva de compreensão do humano apresentada tornou-se fonte de inspiração para a psiquiatria de inspiração fenomenológica, contribuindo para o surgimento de eminentes psicoterapeutas apoiados pela ontologia heideggeriana, a exemplo de Ludwig Binswanger (1881-1966), Eugéne Minkowski (1885-1972) e Medard Boss (1903-1990). Além disso, tem contribuído com alguns campos de conhecimento, tais como a psiquiatria e a psicanálise, através da Dasein, análise proposta por Medard Boss, e da análise existencial de Ludwig Binswanger. E no campo da Psicologia, esse pensamento, juntamente com alguns pressupostos do existencialismo e do método fenomenológico de investigação, tem sido muito difundido, uma vez que orienta o saber-fazer do psicólogo que, por intermédio do encontro com a alteridade, busca explicitar a experiência de sofrimento apresentada pelos demandantes.

Heidegger trouxe contribuições importantes para o saber-fazer psicológico, pois traz à tona a importância do cuidar de ser como condição ontológica/originária do existir humano. Essa inspiração contribui para o advento de uma compreensão do humano para além do dualismo metafísico. Vale destacar que não se trata de fazer Filosofia nem tampouco encaixar a Filosofia heideggeriana na Psicologia. Trata-se de exercer o pensamento originário (por meio do círculo hermenêutico) em prol do resgate do sentido do ser e da superação do psicologismo. Isso poderá contribuir para o desenvolvimento de uma 
praxis psicológica desvinculada de modelos meramente explicativos e lógico-representativos. Isso nos faz vislumbrar possibilidades de novas reconfigurações no trabalho do psicólogo e em seus modos de ser e de estar-no-mundo. Modos que incluem, primordialmente, uma nova forma de se relacionar com o ser das coisas, deixando para trás a arrogância da suposta interpretação total de mundo.

Sendo assim, ao se assumir as inspirações oriundas do pensamento heideggeriano em sua primeira fase produtiva, compreende-se que a Psicologia pode ser construída em uma perspectiva fenomenológica existencial, em que o mais importante não é investigar o psiquismo em suas propriedades, mas, sim, cuidar de ser e permitir que os sentidos se desvelem. Portanto, faz-se necessário empreender novos estudos com foco no "segundo Heidegger", a fim de explicitar suas possíveis contribuições para a prática psicológica na contemporaneidade.

\section{Referências}

ABBAGNANO, N. Introdução ao existencialismo. Tradução de Marcos Marcionilo. São Paulo: Martins Fontes, 2006.

ALMEIDA, F. M. Ser clínico como educador: uma leitura fenomenológica existencial de algumas temáticas na prática de profissionais de saúde e educação. 2005. 215 f. Tese (Doutorado em Psicologia) - Instituto de Psicologia, Universidade de São Paulo, São Paulo, 2005.

BARBOSA, M. F. A noção de Ser-no-mundo em Heidegger e sua aplicação na psicopatología. Psicologia: ciência e profissão, Brasília, DF, v. 3, n. 18, p. 2-13, 1998. Disponível em: <http://pepsic.bvsalud.org/scielo. php? pid $=$ S1414 $-98931998000300002 \&$ script $=$ sci_arttext $>$. Acesso em: 10 abr. 2009.

BARRETO, C. L. B. A ação clínica e os pressupostos fenomenológicos existenciais. 2006. 215 f. Tese (Doutorado em Psicologia) - Instituto de Psicologia, Universidade de São Paulo, São Paulo: USP, 2006.

BARRETO, C. L. B. T.; MORATO, H. T. P. A ação clínica e a perspectiva fenomenológica existencial In: MORATO, H. T.; BARRETO, C. L.; NUNES, A. P. Aconselhamento psicológico numa perspectiva fenomenológico existencial: uma introdução. São Paulo: Guanabara Koogan, 2009. 
BEAINI, T.C. À escuta do silêncio: um estudo sobre a linguagem no pensamento de Heidegger. São Paulo: Cortez, 1981.

BELLO, A. A. Introdução à fenomenologia. Bauru: Edusc, 2006.

BUYS, R. C. A psicologia humanista. In: JACÓ -VILELA, A. M. J.; FERREIRA, A. A. L.; PORTUGAL, F. T. (Org.). História da psicologia rumos e percursos. Rio de Janeiro: Nau, 2007.

CASANOVA, M. A. Compreender Heidegger. Petrópolis: Vozes, 2009.

CIPULLO, M. A. T. O modelo existencial e o pulsional na compreensão da angústia (ou... A escolha de Ubiratan S.). In: ANGERAMI-CAMON, V. A. et al. (Org.). Angústia e psicoterapia. São Paulo: Casa do Psicólogo, 2000. p. 85-103. CRITELLI, D. M. Analítica do sentido: uma aproximação e interpretação do real de orientação Fenomenológica. 2. ed. São Paulo: Brasiliense, 2007.

DARTIGUES, A. O que é a fenomenologia? 10. ed. São Paulo: Centauro, 2008.

DUARTE, R.; NAVES, G. O Ser-para-a-morte em Heidegger. Revista Católica, Uberlândia, v. 3, n. 5, p. 64-82, jan./jul. 2011. Disponível em: <http:// catolicaonline. com.br/revistadacatolica2/artigosn4v2/06-filosofia.pdf>. Acesso em: 22 novembro 2015.

ERTHAL, T. C. S. Abordagem existencial-humanista na psicoterapia. Jornal Brasileiro de Psiquiatria, Rio de Janeiro, v. 35, n. 2, p. 83-90, mar./abr. 1986. Disponível em: <http://bib.pucminas.br/arquivos/120000/121400/25_121494. htm>. Acesso em: 5 ago. 2010.

ERTHAL, T. C. S. Terapia vivencial: uma abordagem existencial em psicoterapia. Petrópolis: Vozes, 1989.

FEIJOO, A. M. L. C. A escuta e a fala em psicoterapia: uma proposta fenomenológico-Existencial. São Paulo: Vetor, 2000.

FElJ00, A. M. L. C. Psicologia clínica e filosofia. Belo Horizonte: Fundação Guimarães Rosa, 2009.

FIGUEIREDO, L. C. M. Matrizes do pensamento psicológico. 5. ed. Petrópolis: Vozes, 1991.

GIORDANI, M. C. Iniciação ao existencialismo. Petrópolis: Vozes, 1997.

GONÇALVES, R. R et al. Merleau-Ponty, Sartre e Heidegger: três concepções de Fenomenologia, três grandes filósofos. Estudos e Pesquisas em Psicologia. 
Rio de Janeiro, ano 8, n. 2, p. 402-435, 2008. Disponível em: <http://www. revispsi.uerj.br/v8n2/artigos/pdf/v8n2a19.pdf>. Acesso em: 17 jul. 2011.

GOTO, T. A. Introdução à psicologia fenomenológica: a nova psicologia de Edmund Husserl. São Paulo: Paulus, 2008.

GREENING, T. et al. Psicologia existencial-humanista. Rio de Janeiro: Zahar, 1975.

HEIDEGGER, M. Carta sobre o humanismo. Rio de Janeiro: Tempo Brasileiro, 1967.

HEIDEGGER, M. Ser e tempo. 8. ed. Petrópolis: Vozes, 1999. pt. 1.

HEIDEGGER, M. Seminários de Zollikon. Petropólis: Vozes, 2001.

HEIDEGGER, M. Sobre o humanismo. São Paulo: Tempo brasileiro, 2009.

HOLANDA, A. F. Questões sobre pesquisa qualitativa e pesquisa

fenomenológica. Análise Psicológica, Lisboa, v. 3, n. 24, p. 363-372, 2006.

Disponível em: <http://www.scielo.oces.mctes.pt/pdf/aps/v24n3/v24n3a10. pdf>. Acesso em: 2 dez. 2010.

INWOOD, M. Heidegger. Tradução de Adaeil Ubirajara Sobral. São Paulo: Loyola, 2004. (Mestres do pensar).

JOLIVET, R. As doutrinas existencialistas. Tradução de portuguesa de Antonio de Queirós Vasconcelos e Lencastre. Porto: Livraria Tavares-Martins, 1953.

LESSA, J. M.; SÁ, R. N. A relação psicoterapêutica na abordagem fenomenológico-existencial. Análise Psicológica, Lisboa, v. 3, n. 24, p. 393397, 2006. Disponível em: <http://www.scielo.oces.mctes.pt/pdf/aps/v24n3/ v24n3a13.pdf >. Acesso em: 7 out. 2010.

LOPARIC, Z. Heidegger. Rio de Janeiro: Zahar, 2004. (Filosofia Passo a passo, v. 32).

MASLOW, A. Introdução à psicologia do ser. 2. ed. Rio de Janeiro: Eldorado, 1962.

MATTAR, C. M.; SÁ, R. N. de. Os sentidos de "análise" e "analítica" no pensamento de Heidegger e suas implicações para a psicoterapia. Estudo Pesquisa Psicologia. Rio de Janeiro, v. 8, n. 2, p. 191-203, 2008. Disponível em: <http://pepsic. bvsalud.org/pdf/epp/v8n2/v8n2a05.pdf>. Acesso em: 17 abr. 2011.

MAY, R. Psicologia existencial. 5. ed. Tradução e ensaio introdutório de Ernani Pereira Xavier. São Paulo: Globo, 1988.

MICHELAZZO, J. C. Do um como princípio ao dois como unidade: Heidegger e a reconstrução ontológica do real. São Paulo: Annablume: FAPESP, 1999. 
MICHELAZZO, J. C. Pensamento e experiência religiosa: contribuições do Jovem Heidegger para a mística apofática. Revista de estudos da religião, Campinas, p. 73-102, dez. 2010

MOREIRA, V. A gestalt-terapia e a abordagem centrada na pessoa são enfoques fenomenológicos? Revista Abordagem Gestáltica, Goiânia,

v. 15, n. 1, p. 3-12, 2009. Disponível em: <http://pepsic.bvsalud.org/scielo. php? pid=S1809-68672009000100002 \&script $=$ sci_arttext\&tlng=es $>$. Acesso em: 14 set. 2010.

NUNES, B. Heidegger \& ser e tempo. Rio de Janeiro: Zahar, 2004. (Passo a passo, v. 6).

PASQUA, H. Introdução a leitura do ser e tempo de Martin Heidegger. Lisboa: Instituto Piaget, 1993.

PENNA, A. G. A fenomenologia e a psicologia fenomenológica: repensando a Psicologia. Rio de Janeiro: Imago, 1997.

PEREZ, S. R. S. Ser-no-mundo com a criança portadora de câncer: compreendendo a experiência de psicólogos nos serviços de oncología pediátrica de natal-RN. 2004. 190 f. Dissertação (Mestrado em Psicologia) Universidade Federal do Rio Grande do Norte, Natal, 2004.

ROGERS, C. Um jeito de ser. Tradução de Maria Cristina Machado Kupfer. São Paulo: EPU, 1983.

SÁ, R. N. A Analítica do Dasein de Martin Heidegger In: FEIJOO, A. M. L. C. (Org.). Tédio e finitude: da filosofia à psicologia. Belo Horizonte: Fundação Guimarães Rosa, 2010.

SÁ, R. N. As influências da fenomenologia e do existencialismo na psicologia. In: JACÓ -VILELA, A. M.; FERREIRA, A. A. L.; PORTUGAL, F. T. (Org.). História da psicologia rumos e percursos. Rio de Janeiro: Nau, 2007. p. 319-338.

SARTRE. J. P. O existencialismo é um humanismo. Tradução de Rita Correira Guedes, Luiz Roberto Salinas Forte e Bento Prado Júnior. 3. ed. São Paulo: Nova Cultural, 1989.

STEIN, E. Os pensadores. Tradução de Ernildo Stein. São Paulo: Abril Cultural, 1979.

ZILLES, U. A fenomenologia husserliana como método radical. In: HUSSERL, E. A crise da humanidade européia e a filosofia. Tradução de Pedro M. S. Alves. Porto Alegre: EDIPUCRS, 2008. p. 27-40. 